ÁREA ABIERTA. Vol.12. n³. NOVIEMBRE 2012

http://dx.doi.org/10.5209/rev_ARAB.2012.v33.40558

Referencia: AA33.1211.169

"EVOLUCIÓN DE LA IMAGEN DEL PRESIDENTE DE ESTADOS UNIDOS EN EL CINE DE ESTEREOTIPOS APOCALÍPTICOS. DE BILL CLINTON A BARACK OBAMA"

AUTORES: Dr. Antonio SÁNCHEZ-ESCALONILLA. Dra. Araceli RODRíGUEZ MATEOS.

Universidad Rey Juan Carlos

\title{
Evolución de la imagen del \\ Presidente de Estados Unidos en el cine de estereotipos apocalípticos. De Bill Clinton a Barack Obama
}

Evolution of the U.S. President's Image in the Cinema of Apocalyptic Stereotypes. From Bill Clinton to Barack Obama 


\section{RESUMEN}

El cine de escenario apocalíptico producido por Hollywood en los últimos años ofrece claves del contexto sociopolítico marcado por los atentados del 11 S. En concreto, ha modificado la representación de uno de los iconos nacionales estadounidenses: el propio presidente. El presente trabajo explora la conexión entre la imagen fílmica de la institución presidencial, por un lado, y la evolución del apoyo popular a las gestiones de Bill Clinton y George W. Bush por otro. El marco de la investigación se extiende al período 1993-2008, y pretende señalar las aportaciones de un género cinematográfico concreto a la configuración de una imagen crítica.

\section{Palabras clave:}

Presidente de Estados Unidos, Cine de desastre, 11-S, seguridad nacional, opinión pública, Guerra de Irak

\section{ABSTRACT}

The Cinema of apocalyptic landscape produced by Hollywood transcodes many features of the socio-political context marked by the 9/1 1 attacks. Specifically, those films have influenced the representation of one of the national icons in the US: the President himself. This paper explores the connection between the filmic portrait of the presidential institution, on the one hand, and the evolution in the approval rating to the jobs of Bill Clinton and George W. Bush on the other. The last two decades are the framework of this research, and it seeks to identify the contributions of a particular cinematographic genre to the critical depiction of this political figure.

\section{Key words:}

U.S. President, Disaster Films, 9/1 1, National Security, Public Opinion, Irak War 


\section{Introducción}

Durante la década los 90, las representaciones fílmicas del presidente de Estados Unidos constituyeron un fenómeno mediático, no solo por su abundante número de apariciones o la variedad de géneros en que surgieron. Como explica Doherty, este fenómeno "tipificó la figura del comandante en jefe como una dramatis persona, unas veces como sólido miembro del entramado pero en la mayoría de las veces como un actor principal de la puesta en escena"l

Tradicionalmente, Hollywood ha proyectado una imagen de la institución presidencial como garante de la defensa ciudadana en tiempos de crisis. Sin embargo, el 115 marcó un punto de giro en la representación de su liderazgo: desde 2001 y en adelante, el personaje presidencial ha sido relegado a papeles secundarios o incluso ha llegado a desaparecer del casting, tanto en géneros de acción como en dramas históricos o políticos. Este progresivo debilitamiento del arquetipo presidencial en el cine del nuevo siglo se perfila como un fenómeno de involución dramática, opuesto al que destaca Doherty en su análisis de los 90. En especial, el deterioro de la imagen presidencial se acusa en los géneros populares de invasión y desastre, guerra, thriller, tramas terroristas y, por extensión, todas aquellas producciones donde la población estadounidense aparece sometida amenaza de destrucción o al pánico consiguiente. Amenaza, destrucción y pánico son, precisamente, claves del imaginario apocalíptico. Y la ausencia del líder supremo en este tipo de cine revela una fractura del vínculo emocional entre audiencia y presidencia.

La aproximación crítica del presente trabajo sigue la senda de los estudios de Kellner, Ryan y Dixon, interpretando las películas en relación a su contexto histórico y buscando los significados sociopolíticos que articulan. En este sentido, García Fernández y Sánchez González argumentan que "la historia y el cine son dos territorios que cada vez se muestran más entrelazados debido, básicamente, a que se complementan de manera enriquecedora desde que los historiadores han comprobado que los reportajes, documentales y las historias de ficción producidas por las más diversas industrias cinematográficas en todo el mundo ayudan a comprender mucho mejor los acontecimientos de toda índole generados desde el último lustro del siglo XIX"2.

En esta línea, la dualidad "presidencia-desastre" en el cine de estereotipos apocalípticos se revela como una clave útil para explorar la mutua realimentación entre cine, opinión pública y discurso político, dentro del campo de los estudios culturales. Además, el grado de apreciación del Presidente en cuanto héroe puede resultar muy elocuente a la hora de establecer alegorías entre la ficción fílmica y la representación unos hechos históricos identificados como "guerra contra el terror" durante un período histórico muy cercano para el ciudadano occidental, en que el cine ha jugado un papel decisivo para la elaboración de imágenes críticas del presidente.

El presente artículo tiene como objetivo analizar el tratamiento y valoración de la figura presidencial en el cine de imaginarios apocalípticos producidos entre 1993 y 2009, tomando el $11 \mathrm{~S}$ como punto de referencia. Para ello se compararán las producciones cinematográficas más populares de los mandatos presidenciales demócrata y republicano inmediatamente previo y posterior al 9/11, según los siguientes criterios empleados en la construcción del arquetipo: relevancia de la figura presidencial en argumentos de desastre o amenaza, actor escogido, discurso político, tendencia heroica o villanesca del personaje, amenaza afrontada y tipo de escenario apocalíptico.

Por otro lado, se pretende comparar la imagen de los mandatarios norteamericanos mostradas en estas películas con los índices de aprobación popular de sus respectivas gestiones al frente de la

\footnotetext{
${ }^{1}$ Doherty, Thomas, "Movie Star Presidents", Jon Lewis (ed.) The End of Cinema as We Know It. American Films in the Nineties, New York University Press, Nueva York, 2001, p. 150

2 García Fernández, Emilio, y Sánchez González, Santiago, “Las imágenes de la historia en la obra de Stanley Kubrick", Área Abierta, n. 1, nov. 2011, p. 1.
} 
administración: la correspondiente a Bill Clinton entre 1993 y 2001, y a George W. Bush entre 2001 y 2009. De este modo, se subrayarán los paralelismos o divergencias entre las ficciones cinematográficas y la opinión pública en torno a la gestión del máximo líder nacional en momentos de amenaza contra la población. En este contexto, conviene recordar la siguiente afirmación de Nelson: "Los estadounidenses pueden describirse como emocionalmente presidencialistas. Casi todos sus héroes políticos del pasado son presidentes (...) El vínculo emocional de los ciudadanos con la presidencia conlleva en sí mismo unas implicaciones que refuerzan su liderazgo"3. No cabe duda de que este vínculo emocional y su reflejo en el cine de amenaza y desastre adquieren una especial relevancia en un período como el señalado, pues permite analizar la estrecha conexión entre fenómenos creativos, mediáticos, políticos y sociológicos en el campo de los estudios culturales.

\section{Orígenes de un miedo endémico al Apocalipsis}

Para hablar del miedo al desastre en el cine, contexto en que se mueve este estudio sobre la imagen del presidente de EE.UU., es preciso remontarse al asentamiento de los Peregrinos en la Roca de Plymouth, sucedido en noviembre de 1620. Según Peter Stearns, la sociedad norteamericana está aquejada de un miedo endémico tradicional desde los tiempos coloniales: su propia destrucción. Para este investigador, "la arquitectura principal del miedo americano procede de fuentes diferentes, incluso contradictorias, pero nunca se ha librado de los recurrentes miedos raciales ni de la persistente expectativa de algún tipo de castigo divino"4.

A la vuelta de cuatro siglos, Stearns considera el miedo al desastre como uno de los más activos en la sociedad estadounidense, hasta el punto de identificarlo como una verdadera subcultura viviente. Más aún, Stearns aprecia en nuestros días una intensificación del miedo al castigo apocalíptico: "Determinados elementos poderosos afloraron en el resurgimiento americano y en las anticipaciones del segundo milenio (e incluso ahora, mientras esperamos el 2012 de los mayas). Las creencias de minorías dispersas en la inminencia de la segunda venida y del fin del mundo -que provocan una mezclan de miedo y euforia-, siguen alimentando estas corrientes obstinadas" 5 . Resulta paradójica la popularidad de este género entre los norteamericanos, que durante décadas han acudido en masa a los cines para contemplar la destrucción de sus ciudades y símbolos nacionales. Este fenómeno creativo y mediático constatado mucho antes del 1156, se ha visto modificado en los años posteriores debido a la diferencia de contextos sociopolíticos.

La espectacularidad visual de la propia catástrofe y el secular temor al desastre son dos elementos inseparables a la hora de plantear una ficción apocalíptica en el cine. Pero si a esto se añaden los referentes religiosos, idiosincráticos y culturales del imaginario norteamericano, las posibilidades críticas del relato fílmico adquieren un renovado valor dentro del contexto de los estudios de cine y de los estudios culturales. La cuestión se ha enriquecido con diversas aportaciones. Thompson interpreta las ideas apocalípticas en el cine del final del milenio enfatizando la conexión religiosa, mientras que Sharrett vincula ese miedo a los rasgos del pensamiento postmoderno, entre los que destaca la crisis de identidad del sujeto contemporáneo ${ }^{7}$. Kellner, por su parte, entiende que, además de estos factores influyentes, las visiones apocalípticas del cine y la cultura popular norteamericana conectan directamente con los miedos derivados de la evolución en el contexto político, económico y medioambiental desde los años ochenta. En otras palabras, el temor

\footnotetext{
${ }^{3}$ Nelson, Michael, "Evaluating the Presidency", Ed. M. Nelson. The Presidency and the Political System. Washington, D.C.: CQ Press, 2006, p. 14.

${ }^{4}$ STEARNS, Peter N., American Fear: The Causes and Consequences of High Anxiety, Routledge, Nueva York, 2006, p. 74.

${ }^{5}$ STEARNS, Peter N. "Targeting American Fear" Revie Française d'Etudes Americaines 3/2010 no 125: p. 10.

${ }^{6}$ Cfr. KELLNER, Douglas y RYAN, Michael, Camera Politica: The Politics and Ideology of Contemporary Hollywood Film, Indiana University Press, Bloomington, 1988.

${ }^{7}$ Cfr. THOMPSON, Kirsten Moana, Apocalyptic Dread: American Film at the Turn of the Millennium, State University of New York Press, Albany, 2007; SHARRET, Chris (ed.), Crisis Cinema: The Apocalyptic Idea in Postmodern Narrative Film, Maisonneuve Press Washington DC, 1993.
} 
apocalíptico en el cine traducía un miedo instalado en la sociedad frente al peligro real de colapso, sobre todo en los últimos años 8 .

Lo cierto es que para muchos ciudadanos norteamericanos, el 115 supuso el cumplimiento de las peores profecías advertidas por analistas políticos, propagadas por Hollywood o alimentadas por sectas protestantes milenaristas. En 1999, una encuesta del Pew Research Center de Chicago señalaba que el 64 por ciento de los norteamericanos esperaba que se produjera un ataque terrorista a gran escala en los siguientes cincuenta años. Diez años después del 11S, si bien el porcentaje había descendido hasta el 53 por ciento, la proporción de ciudadanos temerosos de una nueva jornada fatal continuaba resultando significativa?.

La amenaza contra la población y los efectos psicológicos del desastre aparecen reflejados en el cine a través de argumentos que, sin pertenecer al género específico de catástrofes, conectan con este imaginario popular apocalíptico. Por este motivo, al plantear una exploración de la amenaza destructiva en el cine, resultaría más apropiado referirse a "escenarios apocalípticos" o "visiones apocalípticas"10, y no ceñirse exclusivamente al género de catástrofes.

En efecto, el imaginario apocalíptico es un concepto transversal que podemos encontrar en distintos géneros, aunque no estén relacionados directamente con la recreación material de una catástrofe. Los elementos de este imaginario son fácilmente reconocibles cuando aparecen organizados en un argumento según la estructura peculiar de los géneros de fórmula, que Cawelti opone a los géneros miméticos ${ }^{11}$. Según esta distinción fundamental de géneros, el desastre ofrece fórmulas argumentales cerradas y recurrentes en todas sus variables (invasión alienígena, desastre natural, epidemia...), y en todas ellas el espectador puede reconocer una trama maestra donde una comunidad afronta una determinada amenaza de destrucción $y$, purificada durante la experiencia, se sobrepone a ella.

Sin embargo, los elementos del imaginario apocalíptico también pueden aparecer en relatos fílmicos pertenecientes a géneros miméticos, ajenos a la estructura de una fórmula, tal como sucede en los dramas. Por este motivo, en nuestro estudio también se consideran películas clasificables en géneros miméticos, donde el agente defensor de la comunidad-ya sea una agencia de seguridad, un cuerpo militar o un político- esté asociado al presidente de Estados Unidos o a la institución presidencial. Además, también conviene considerar aquellas producciones que, pese a no incluir elementos del imaginario apocalíptico, han contribuido a forjar una determinada imagen de un líder que, como Comandante en Jefe de las Fuerzas Armadas, asume la defensa del país ante cualquier amenaza. Más allá de un personaje concreto, la visualización fílmica de esta figura también se extiende a una iconografía habitual en el cine, manifestada a través de un edificio representativo (la Casa Blanca), un colectivo militar (las Fuerzas Armadas, de las que el presidente es su máxima autoridad), un colectivo de seguridad (la Agencia Central de Inteligencia), miembros de su Administración (como el Vicepresidente o el Secretario de Defensa), o una aeronave singular (el Air Force One).

\section{Imagen heroica del presidente durante los noventa}

La figura del presidente de los Estados Unidos en el cine de los años 90 viene marcada por dos tendencias: una opinión pública que respalda la gestión de Bill Clinton entre 1993 y 2001, en un

\footnotetext{
${ }^{8}$ Cfr. KELLNER, Cinema Wars, op. cit.

9 "Public Sees a Future Full of Promise and Peril", Pew Research Center for the People and the Press, 22-06-2010, http://people-press.org/2010/06/22/public-sees-a-future-full-of-promise-and-peril, 08-11-2011.

${ }^{10}$ Cfr. DIXON, Wheeler W., Visions of the Apocalypse: Spectacles of Destruction in American Cinema, Wallflower Press, Londres, 2003.

${ }^{11}$ Cawelti advierte que los géneros miméticos "nos enfrentan con el mundo tal y como lo conocemos, mientras que los géneros de fórmula reflejan la construcción de un mundo ideal desprovisto del desorden, la ambiguedad, la incertidumbre y las limitaciones del mundo de nuestra experiencia. Cfr. CAWELTI, John, Adventure, Mystery and Romance: Formula Stories as Art and Popular Culture, University of Chicago Press, Chicago, 1976, p. 13.
} 
contexto general de prosperidad, y por otro lado el tratamiento favorable que recibe la institución presidencial en las producciones cinematográficas de la década. Sobre estas bases se asienta la representación dramática de la figura del presidente, tanto en el cine de escenarios propiamente apocalípticos como en el de escenarios pre-apocalípticos.

La creciente popularidad del presidente Clinton a lo largo de sus dos mandatos puede apreciarse en los siguientes datos: durante el primero, una media del 50 por ciento de la población aprobaba su gestión, media que ascendió al 60 por ciento durante el segundo período. Clinton alcanzó la cota máxima de su popularidad (73 por ciento) en diciembre de 1998, dos años antes de abandonar el poder, según datos de Gallup ${ }^{12}$.

Esta predisposición favorable del espectador norteamericano se reforzó a lo largo de la década con la aparición sucesiva de títulos, casi siempre biopics y blockbusters de acción, donde la imagen y liderazgo de los personajes presidenciales quedaban ensalzados, reforzados y, en algunos casos, justificados ante decisiones controvertidas.

La figura presidencial en el cine de los 90 está condicionada por el éxito de J.F.K. (Oliver Stone, 1991), donde el ideario de Kennedy y su programa parecían preconizar el triunfo de Clinton. Primary Colors (Mike Nichols, 1998), por otra parte, aparece a finales de la década para ofrecer una semblanza de los esposos Stanton en su carrera hacia la Casa Blanca, con un argumento donde la avidez política de la pareja (émulo de los Clinton) queda purificada mediante la recuperación de los valores demócratas inspirados por Kennedy en los 60. Además, la tendencia positiva de la imagen presidencial quedó reforzada con contribuciones menores como las de Steven Spielberg en Amistad (1997) y Salvar al soldado Ryan (1988). Anthony Hopkins interpretó en la primera al expresidente John Quincy Adams, abogado que consigue la absolución del grupo de esclavos afroamericanos. En la segunda, el espíritu de Abraham Lincoln es invocado por el general Marshall antes de aprobar la misión de rescate del comando protagonista.

En estos ejemplos fílmicos, la figura del presidente resulta amable y cercana, y queda asociada a la defensa de los valores democráticos. Incluso en Nixon, Oliver Stone presenta en 1995 un relato indulgente y humanizado del único presidente republicano que abandonó el cargo por un escándalo de espionaje político. Ese mismo año, la comedia romántica The American President, protagonizada por Michael Douglas, refuerza la amabilidad de la institución.

Sobre la base de esta representación fílmica de balance positivo, el cine apocalíptico introduce la figura presidencial como líder y referente de una comunidad sometida a una amenaza de destrucción. Así queda de manifiesto en dos historias de distinto género que suceden en escenarios pre-apocalípticos: Air Force One (Wolfgang Petersen, 1997) y Trece días (Kenny O'Donnell, 2000). En la primera, el presidente se enfrenta al ataque de un grupo terrorista asiático a bordo del propio avión presidencial, precisamente tras exponer su política de "tolerancia cero" con el terrorismo mundial en una cumbre celebrada en Moscú. En la segunda, se recrea la crisis de los misiles ocurrida en octubre de 1962, cuando Kennedy consiguió la retirada de barcos soviéticos provistos de cabezas nucleares que, una vez instalados en Cuba, apuntarían hacia territorio norteamericano.

En ambos ejemplos, el presidente previene y evita la amenaza de la comunidad ciudadana. En el caso de Air Force One, la propia familia del presidente se halla a bordo del avión y este factor estrecha la cercanía entre el líder y su pueblo. Tanto Marshall (nombre ficticio, aunque muy sugerente) como Kennedy son presentados como presidentes con experiencia militar y condecorados respectivamente en la segunda guerra mundial y en Vietnam. La frase promocional de la primera, "The Fate of a Nation Rest on the Courage of One Man", ensalza el icono

\footnotetext{
12 “Presidential Approval Ratings: Bill Clinton”, Gallup, 09-2011, http://www.gallup.com/poll/116584/ presidential -approval-ratings-bill-clinton.aspx, 09-09-2011.
} 
presidencial, mientras que el tagline de la segunda, "You'll Never Believe How Close We Come", subraya la cercanía de la amenaza de destrucción nuclear que gravitó sobre la población estadounidense.

El uso de la imagen de Kennedy como referente presidencial de Hollywood en los 90 queda también de manifiesto en el recurso a Gary Oldman para representar papeles antagonistas. En efecto, tras interpretar a Lee Harvey Oswald en J.F.K., el actor encarnó al líder terrorista de Air Force One y al villano visionario de El quinto elemento (Lucc Besson, 1997), película donde un presidente afroamericano en los Estados Unidos del siglo XXIII afronta una posible hecatombe planetaria.

Sin duda alguna, los blockbusters Independence Day (Roland Emmerich, 1996) y Deep Impact (Mimi Leder, 1998) destacan, entre los títulos mencionados, por su importancia en la consolidación de la figura presidencial en relatos específicamente apocalípticos de los 90. La película de Emmerich presenta al presidente norteamericano Thomas J. Whitmore como líder y veterano de guerra, que no duda en pilotar un caza de las Fuerzas Aéreas para derribar extraterrestres invasores. Su liderazgo político queda asociado al ejército, enfrentado a unos alienígenas que amenazan con exterminar no sólo la comunidad que representa, sino a todo el planeta. Al mismo tiempo, la producción recrea de manera espectacular la destrucción de edificios emblemáticos del país, como la Casa Blanca o la US Bank Tower de Los Angeles. Previamente, la sombra de una nave extraterrestre ha sumido en una oscuridad premonitoria la imagen sedente del Lincoln Memorial.

Si los alienígenas de Emmerich podrían equipararse con la plaga de langostas del libro del Apocalipsis, el cometa de Deep Impact vendría a ser la estrella Absinthius o uno de los numerosos astros que se precipitan sobre la tierra. Una de las peculiaridades de la película de Mimi Leder consiste en la presentación del millón de norteamericanos elegidos que, como los 144.000 sellados del texto bíblico, son escogidos para entrar en el gigantesco refugio que les protegerá de la extinción. Las tramas recurrentes de sacrificio y purificación también aparecen en el guión, y entre ellas destacan las que protagonizan los tripulantes de la misión espacial Messiah, que terminarán inmolándose para partir el cometa en dos.

La figura presidencial de Deep Impact está representada por el actor Morgan Freeman. Si bien no se trata de un presidente soldado, el personaje presenta un sólido carisma moral reforzado por la elevada categoría de otros personajes previamente interpretados por el actor, en especial en títulos como Glory (1989), Paseando a Miss Daisy (1989), Cadena perpetua (1995) y Amistad (1997). Beck, el presidente de Deep Impact, posee la ecuanimidad y templanza necesarias para manejar la crisis, preparar las tareas de evacuación y coordinar la misión espacial. El mensaje que dirige a la nación, con sus apelaciones al sacrificio y a la oración, refuerza la autoridad ética del líder político.

En Mars Attacks! (1996), Tim Burton realiza una parodia del cine de invasión y desastre a través de los referentes del género establecidos en los años 50. La figura presidencial también aparece en esta producción, interpretada esta vez por Jack Nicholson: un actor que, dado su curriculum de interpretaciones, no ofrece las mismas garantías morales ni inspira la misma confianza que Morgan Freeman. Cierta crítica no terminó de aceptar el tono iconoclasta de la película y Kenneth Turan, de Los Angeles Times, escribió que Mars Attacks!, con su burla de América y de los símbolos nacionales que Independence Day tomaba seriamente, rebosaba todo el cinismo y el escepticismo de los $90^{13}$. Sólo se trata de un comentario, pero el reproche de Turan gana fuerza si se sitúa en perspectiva y se compara con el uso que, por entonces, Hollywood se atrevía a hacer con la imagen del presidente Clinton, recreado digitalmente para interpretarse a sí mismo como benefactor de un formidable programa espacial en Contact (Robert Zemeckis, 1997), O representado junto a su esposa en el melodrama Quédate a mi lado (Chris Columbus 1998) por dos niños que se disfrazan en la fiesta escolar del Día de Acción de Gracias.

13 TURAN, Kenneth, “Mars Attacks!: Tim Burton's Plan 9”, Los Angeles Times, 13-12-1996, http://articles.latimes.com/1966-12-13/entertainment/ca-8507 1 mars-attacks, 09-09-2011. 


\section{Devaluación de la figura presidencial}

A diferencia de lo sucedido en la década anterior, el primer mandato de George W. Bush viene marcado por la indiferencia de Hollywood ante la figura presidencial, en particular en lo referente a argumentos de catástrofe o de escenario apocalíptico.

Los primeros ocho meses de George W. Bush en la Casa Blanca apenas tuvieron notoriedad social, pese al contencioso que marcó las elecciones de noviembre de 2000. Es importante anotar ya que la polémica sobre el recuento de votos en Florida marcó esta administración desde su inicio: una parte de la opinión pública estadounidense -los votantes no republicanos- entendió que Bush había llegado al poder de forma poco clara, como mínimo. Aunque el discurso mediático dominante no fue crítico, tampoco faltaron voces que denunciaron lo que consideraban un fraude electoral, avivando un debate sobre los fallos en el sistema de votación que se volvería a repetir en las elecciones de 2004, con lo ocurrido en Ohio ${ }^{14}$. Con independencia de la gestión republicana, la legitimidad democrática del presidente era cuestionada por parte de la ciudadanía, lo que ciertamente constituía una situación excepcional. El cine documental lo expuso directamente en títulos como Unprecedented (Ray y Sekler, 2001) y el cine de ficción no fue ajeno a esa percepción de figura desprestigiada, como veremos.

Sin embargo, los ataques terroristas del $11 S$ transformaron la opinión pública norteamericana y la propia imagen de Bush: en pocos días, la aprobación popular de la gestión presidencial ascendió desde un escaso 50 por ciento hasta superar los 86 puntos $^{15}$. El pueblo se mostraba ampliamente partidario del uso de la fuerza militar para combatir el terrorismo y, según Kellner, fue considerado no patriótico atacar al presidente y a la administración ${ }^{16}$. Pero las complicaciones surgidas en el conflicto de Irak, la reacción ante el desastre de Katrina y el resultado negativo de medidas sociales, políticas y económicas marcaron una administración turbulenta y provocaron un desgaste progresivo de la imagen de Bush en su segundo mandato. A finales de 2008, en pleno colapso del sistema financiero, la aprobación popular de su gestión apenas alcanzaba el 25 por ciento. La curva descendente de Bush en apreciación popular entre 2001 y 2009 contrasta llamativamente con el ascenso inverso de Bill Clinton entre 1993 y 2001, también a lo largo de dos mandatos. Esta tendencia negativa -la decadencia de su figura- tendría su reflejo en el cine, y de una manera especial en los títulos de elemento apocalíptico.

Como se ha visto, la figura presidencial aparecía vinculada en los 90 a una imagen predominantemente heroica en argumentos de desastre o amenaza civil. Si entonces se trató de una tendencia espontánea, tras el $11 \mathrm{~S}$ la Casa Blanca intentó elaborar un discurso patriótico mediante una estrategia en la que Hollywood debía jugar un papel primordial. Así, en diciembre de 2001, se convocaron diversas reuniones entre miembros de la Administración Bush-Cheney y ejecutivos de la industria de Hollywood, con objeto de establecer una base ideológica que sirviera de apoyo a la iniciativa bélica. En uno de los encuentros, mantenido en Beverly Hills, los representantes del gobierno invocaron el papel patriótico de la industria del cine durante la segunda guerra mundial y se propuso que todo material fílmico relacionado con temas bélicos expresara siete aspectos concretos, entre ellos: "Los ciudadanos norteamericanos deberán apoyar a las tropas de Estados Unidos y a sus familias", "El atentado del 11 de septiembre fue un ataque global y requiere una respuesta global", y "Esta es una guerra contra el mal"17.

La primera respuesta a la llamada de la Casa Blanca fue The Spirit of America (2001), una película de montaje rápido dirigida por Chuck Workman que consistía en una sucesión de los héroes más famosos del cine americano, destacados por su honor y su espíritu vengativo. La película, un

\footnotetext{
${ }^{14}$ Cfr. KELLNER, Media Spectacle, 2005.

15 "Reviewing the Bush Years and the Public's Final Verdict. Bush and Public Opinion", The Pew Research Center, $18-$ 12-2008, http://people-press.org/2008/12/18/bush-and-public-opinion, 12-09-2011.

16 KELLNER, Cinema Wars, op. cit., p. 34.

${ }^{17}$ HAYES, Dade and McCLINTOCK, Pamela, "War chores for H'w'd: White House, moguls agree to step up showbiz efforts", Variety, 11-11-2001, http://www.variety.com/article/VR1117855616? refcatid=18\&printerfriendly=true, 21-092011.
} 
cortometraje de tres minutos, concluía sintomáticamente con la imagen de Ethan Edwards, el héroe de Centauros del desierto (1956) interpretado por John Wayne. La respuesta de Hollywood a la llamada oficial no dio mucho más de sí, y la industria del cine se limitó a evitar el 115 de forma deliberada entre 2001 y 2004. Por otro lado resulta evidente que, durante el primer mandato de Bush, la figura del presidente aparece desprovista de cualquier sentido heroico en las dos únicas producciones de desastres o amenaza apocalíptica más relevantes de ese período: Pánico nuclear (Phil A. Robinson 2002) y El día de mañana (Roland Emmerich, 2004). Más aún, se trata de títulos en los que el presidente toma decisiones controvertidas para la seguridad de los ciudadanos en momentos críticos.

Pocos meses después del 11S, Pánico nuclear, basada en un best seller de Tom Clancy, presenta el escenario de una crisis nuclear entre Estados Unidos y Rusia agravada por una decisión precipitada del presidente norteamericano Fowler, que ordena un ataque nuclear masivo de represalia contra objetivos militares rusos. Fowler estaba interpretado por James Cromwell, cuya imagen adusta distaba bastante de la ofrecida por otros presidentes encarnados en el pasado por Harrison Ford o Morgan Freeman. Al realizar la adaptación de la novela, los productores transformaron en terroristas neonazis a los fanáticos musulmanes que provocan la crsisi. En cambio, mantuvieron la imagen debilitada de un presidente norteamericano que manejaba asuntos de seguridad de manera irresponsable.

El día de mañana -séptimo en el ranking de taquilla de 2004, por debajo de títulos como Shrek II (Andrew Adamson), Spider-Man II (Sam Raimi) y La pasión de Cristo (Mel Gibson)-, aventura el escenario apocalíptico de un inminente cambio climático. La película de Emmerich fue la primera producción que recreó escenas de pánico entre los habitantes de Nueva York tras el 11S, y en ella el director trataba la figura del presidente de Estados Unidos de un modo muy distinto a Independence Day: si en ésta un presidente soldado pilota su aeronave para enfrentarse a la amenaza y defender a sus ciudadanos, en El día de mañana el presidente sube a un helicóptero para huir de la supertormenta que, finalmente, le hará sucumbir. El contraste de ambas acciones y sus significados implícitos -atributos de heroísmo versus cobardía- son elocuentes del giro en la imagen del líder, que sustituye el patrón presidente-soldado por el de presidente-víctima.

Alegóricamente, Emmerich puso de manifiesto la falta de previsión de la Casa Blanca y su escepticismo ante la amenaza de desastre climático, lo que en la cinta tiene consecuencias devastadoras. De hecho, retrató al presidente como un líder incompetente, sobrepasado por los acontecimientos. Pero también incluyó un ataque velado contra la llamada Patriot Act de octubre de 2001, denunciada por la American Civil Liberties Union por permitir "maltrato de inmigrantes, la supresión de la crítica y de la investigación, y la vigilancia de ciudadanos absolutamente inocentes"18 (ACLU). Así, resulta irónico que el presidente de El día de mañana ordene la evacuación al sur del Río Grande de sus propios ciudadanos, obligados a entrar en México como ilegales.

\section{Desaparición del primer ciudadano en la pantalla}

Como se ha mencionado, a lo largo del segundo mandato de la Administración Bush-Cheney, la valoración popular de la gestión presidencial sufre un descenso imparable desde el 50 hasta el 24 por ciento 19. Al mismo tiempo, entre 2005 y 2008 se experimenta un auge renovado del cine de invasión y catástrofes, mientras que en títulos de género diverso -en especial cintas bélicasabundan las alusiones a escenarios y visiones de carácter pre-apocalíptico. Kellner relaciona ambos hechos de la siguiente manera: "En la era Bush-Cheney surgieron alegorías del desastre y visiones de catástrofes sociales, desde películas de desastres ecológicos a un gran número de visiones distópticas del futuro, dentro de una mezcla de ciencia-ficción y horror. Allá donde

18 "ACLU Responds to Senate Passage of Anti-Terrorism Bill, Ashcroft Speech. Promises to Monitor Implementation of Sweeping New Powers", American Civil Liberties Union, 25-10-2001, http://www.aclu.org/natsec/gen/12464prs20011025.html, 22-09-2011.

19 "Reviewing the Bush Years" 
proliferara la angustia social, el cine y la fantasía evocaba el apocalipsis social, una alegoría evidente en el cine de Hollywood del nuevo siglo que articula las preocupaciones en torno a la crisis medioambiental y el colapso socioeconómico y político"20. En consonancia con esta percepción, si en el primer mandato de Bush se había apreciado una devaluación de la imagen presidencial en el cine de amenaza popular, la figura del presidente de Estados Unidos experimentará a partir de 2005 un deterioro manifiesto como líder en la dramatización de situaciones críticas.

En los diecisiete títulos de invasión, catástrofe o escenario apocalíptico de este segundo período, el personaje presidencial se encuentra ausente mientras la población, desprovista de líder, queda sometida a la masacre. Así sucedía en La guerra de los mundos (Steven Spielberg 2005), durante una invasión extraterrestre que, en palabras de su director, equiparaba a la población norteamericana con la iraquí: "Tras el 11S, La guerra de los mundos es una reflexión de lo asustados que estamos. Esta película convierte a las familias norteamericanas en refugiados, algo que Estados Unidos nunca ha experimentado"21. El presidente también se encuentra ausente en otras películas de desastres como La niebla (Frank Darabont 2007), El incidente (M. Night Shyamalan 2008) 0 Monstruoso (J.J. Abrams 2008), e incluso en remakes de clásicos como las discretas La invasión (Oliver Hirschbiehel 2007) y Ultimátum a la Tierra (Scott Derrickson 2008).

La ausencia presidencial resulta especialmente elocuente en las dos únicas producciones de envergadura que, cinco años después, recreaban sucesos históricos del 11s: World Trade Center (Oliver Stone 2006) y United 93 (Paul Greengrass 2006). Ambos títulos ponían el acento en el heroísmo de ciudadanos anónimos, concretamente una pareja de bomberos en la Zona Cero y los pasajeros del avión que, presuntamente dirigido contra la Casa Blanca o el Capitolio, terminó estrellándose en Pensilvania. La imagen de Bush dirigiéndose al pueblo con un megáfono, junto a las ruinas de las torres gemelas, había asociado la figura presidencial con el heroísmo ciudadano. Sin embargo, nada quedaba en estos dos títulos de aquel icono que, por entonces, reflejaba el 86 por ciento de aprobación popular alcanzado por Bush a finales de 2001.

Las breves apariciones del personaje presidencial en el cine de amenaza del momento pueden considerarse anecdóticas, como si se tratara de un elemento más del escenario apocalíptico. Así sucede, por ejemplo, en títulos de 2007 como Soy leyenda (Francis Lawrence) y La jungla 4.0 (Len Wiseman). En la primera, la voz presidencial se escucha por la radio -con un acento muy similar al de Dick Cheney- para declarar Nueva York en cuarentena. En la segunda, los ciber-terroristas emiten un ultimátum por televisión mezclando extractos de discursos televisivos de diferentes presidentes de Estados Unidos, desde Roosevelt a Kennedy. Entre estas frases destaca una de las más famosas, pronunciada por el propio George W. Bush en un discurso ante el Congreso nueve días tras los ataques del 11s: "No nos cansaremos, no vacilaremos y no fallaremos". Tras su emisión, uno de los terroristas comenta en tono irónico: "Traté de encontrar más imágenes de Nixon".

En otros ejemplos, también de manera tangencial pero menos inocua, la figura del presidente quedaba unida a la amenaza popular en dos títulos de animación con escenario apocalíptico: Wall-E (Andrew Stanton 2008) y Los Simpson. La película (David Silverman 2007). En el filme de Pixar, el Global CEO de Buy N Large Corporation, multinacional que ha causa la ruina ecológica del planeta, aparece como un personaje de carne y hueso que, asemejado al presidente de Estados Unidos ante el atril de la Casa Blanca, comunica el desastre a la población mundial. En la segunda, un presidente de escasa habilidad llamado Arnold Schwarzenegger es forzado por el jefe de la Enviromental Protection Agency para que encierre a la población de Springfield dentro de una gigantesca campana de cristal, en prevención de un desastre ecológico. A continuación, el jefe de la EPA consigue que el presidente ordene la completa destrucción de la ciudad y sus habitantes.

${ }^{20}$ KELLNER, Cinema Wars, op. cit., p. 81.

21 BARBOZA, C., "Imagination is infinite", USA Weekend, 19-06-2005, http://www.usaweekend.com/ 05_issues/050619spielberg.html, 09-11-2008. 
Desde las elecciones de 2004, el deterioro de la imagen presidencial es una tendencia generalizada en el cine, que puede comprobarse abiertamente en dramas de análisis político como El asesinato de Richard Nixon (2004), W (Oliver Stone 2008), El desafío. Frost contra Nixon (Ron Howard 2008), o en la polémica Muerte de un presidente (Gabriel Range 2006), falso documental sobre la investigación del asesinato de George W. Bush en Chicago. Además, durante el segundo mandato republicano se advierte en las producciones de ficción de Hollywood una reacción contra el discurso patriótico de Bush en materia de seguridad, en especial tras las complicaciones de la guerra de Irak y el aumento de las bajas norteamericanas. Concretamente, en títulos de género bélico y en thrillers de acción abundan alusiones críticas a la política presidencial en materia de seguridad, a través de argumentos que transcurren en escenarios pre-apocalípticos, donde el ejército o las agencias de seguridad tratan de alejar el Armageddon del territorio nacional.

En esta la línea se encuentran títulos como El expediente Anwar (Gavin Hood 2007) y Red de menrtiras (Ridley Scott 2008). Ambas producciones están protagonizadas por agentes de la CIA especializados en prevención de terrorismo islamista, que terminan cuestionando o dimitiendo de sus puestos tras comprobar los métodos inhumanos de los interrogatorios. La hipótesis de una estructura inmoral viciada dentro de las agencias de seguridad estatales, ajena al control del presidente, es precisamente el argumento de Conspiracián del pánico (D.J. Caruso 2008), en la que un supercomputador del Pentágono planea y ejecuta un plan para asesinar al presidente. Hacia el final de la película, el Secretario de Defensa pronuncia una frase que sintetiza toda una reflexión sobre las medidas de seguridad de Patriot Act: "A veces las propias medidas que tomamos para salvaguardar nuestra libertad se convierten en amenazas para la misma libertad".

\section{Ejércitos de Hollywood sin Comandante en Jefe}

El analista Bob Woodward -especialmente crítico con la Administración Bush durante su segundo mandato22-, señalaba en 2002 que la guerra contra el terror denominada operación "Justicia infinita", después renombrada como "Libertad duradera", había proporcionado el contexto profético necesario para inspirar una retórica de corte apocalíptico, que situaba el Armageddon en Oriente Medio y demonizaba la figura de Saddam Hussein ${ }^{23}$. El líder iraquí, por su parte, había contribuido a esta retórica peculiar tras referirse a sí mismo como la reencarnación de Nabucodonosor, el antiguo rey babilónico.

Cuatro meses después del 11S, el presidente pronunciaba su discurso a la nación y por primera vez empleaba la expresión eje del mal para referirse a los potenciales agentes destructivos que amenazaban la paz y las comunidades alineadas con el mundo civilizado: "Estados como estos y sus aliados terroristas constituyen un eje del mal, armado para amenazar la paz del mundo. Pretendiendo la construcción de armas de destrucción masiva, estos regímenes suponen un grave y creciente peligro. Podrían proporcionar estas armas a los terroristas, dándoles los medios que se ajustan a su odio. Podrían atacar a nuestros aliados o intentar extorsionar a los Estados Unidos. En cualquiera de estos casos, el precio de la indiferencia sería catastrófico"24.

Como se ha visto, Hollywood tardó en reflejar la guerra contra el terror en el cine, pero cuando lo hizo prescindió del discurso patriótico promovido por el propio Comandante en Jefe del ejército. En cambio, el papel del ejército sí sería tratado a través del género bélico y de desastres, como una longa manus presidencial.

Entre los títulos apocalípticos mencionados atrás, el caso de La niebla resulta especialmente significativo si se tiene en cuenta que el propio ejército supone la causa de la catástrofe. Según el guión, basado en un relato de Stephen King, los monstruos que aterrorizan a la población de la

\footnotetext{
${ }^{22}$ Cfr. WOODWARD, Bob, State of Denial, Simon\&Schuster, Nueva York, 2006.

${ }^{23}$ WOODWARD, Bob, Bush at War, Simon\&Schuster, Nueva York, 2002, p. 67.

24 "President Delivers State of the Union Address", The White House, Office of the Press Secretary, 29-01-2002, http://georgewbushwhitehouse.archives.gov/news/releases/2002/01/print/20020129-11.html, 12-09-2011.
} 
costa este irrumpen en nuestro mundo desde un universo paralelo, a través de una brecha abierta durante experimentos de inteligencia militar. En otro título de género distinto, el drama En el Valle de Elah (2007), Paul Haggis ofrece una imagen controvertida del ejército de Estados Unidos a través de un padre que investiga la desaparición de su hijo, un soldado recién llegado de Irak, para terminar descubriendo que ha sido asesinado por sus propios compañeros. La escena terrible del padre reconociendo los restos del hijo, reducidos a un sencillo cráneo, traslada la visión del Apocalipsis al ámbito doméstico y despierta en el personaje -militar retirado- una reflexión sobre la patria amenazada, no por agentes externos sino por sus propios poderes. Haggis señala además la paradoja de una guerra que, iniciada como la liberación del pueblo iraquí, ha transformado en asesinos a sus propios soldados.

La presentación de la población americana, indefensa ante un cambio de papeles en la guerra, queda también expresada en la inversión del símbolo apocalíptico del Armageddon, como ya había hecho Spielberg en La guerra de los mundos. Tanto en este título como en los de Darabont y Haggis, el escenario bíblico donde debe suceder la guerra definitiva de liberación contra las fuerzas del mal (elemento clave en el discurso patriótico de Bush para justificar la guerra de Irak), se traslada al hogar de los elegidos en forma de castigo purificador. Esta inversión de papeles entre la población iraquí y la población americana también se produce en Monstruoso, cuyos protagonistas terminan sepultados entre los escombros del Central Park, después de que el ejército destruya Manhattan con una bomba atómica.

Hacia 2008, la imagen del presidente que pilota un caza y lidera una escuadrilla para defender a su población quedaba bastante lejana. La figura presidencial no sólo se elude en el cine de escenarios apocalípticos, sino que llega a equipararse con las fuerzas destructoras a través del ejército bajo su mando. En este sentido, la semejanza entre el ejército y los ángeles exterminadores ofrece otro ejemplo de inversión simbólica. Pero el cine de invasión y desastres del segundo mandato republicano ofrece también una segunda alegoría apocalíptica a través de un arquetipo tradicional en la subcultura religiosa señalada por Stearns: el personaje iluminado que, como los pioneros del siglo XVII, cree pertenecer a un pueblo elegido.

La alusión a este arquetipo puede considerarse una respuesta al componente mesiánico de una parte del discurso adoptado por Bush tras el 11S. Por ejemplo, tres días después de la jornada trágica, el presidente intervino en la Catedral Nacional de Washington con motivo del National Day of Prayer and Remembrance, y se refirió al papel que la nación debía desempeñar ante el mundo: "Nuestra responsabilidad con la historia es clara: responder a estos ataques y librar al mundo del mal". Hacia el final de su alocución, Bush apeló al espíritu fundacional de los Estados Unidos: "En cada generación, el mundo ha producido enemigos de la libertad humana. Ellos han atacado América porque somos la patria y los defensores de la libertad, y aquel compromiso de nuestros Padres es ahora la llamada de nuestro tiempo"25.

El arquetipo del iluminado atrincherado aparece en La guerra de los mundos, La niebla y El incidente, encarnado en las figuras del francotirador Ogilvy, la fanática Mrs. Carmody y la anciana solitaria Mrs. Jones. Los dos primeros se muestran como personajes atrincherados que intentan escapar de monstruos extraterrestres y que, arrastrados por su propia paranoia religiosa, terminan amenazando o provocando la muerte de otros refugiados. En el caso de Mrs. Jones, el fanatismo queda atenuado por un especie de locura solitaria, igualmente letal para los protagonistas supervivientes que se esconden en su casa.

\section{El inicio de la Era Obama}

La victoria electoral de Barack Obama en noviembre de 2008 coincidió con dos datos estadísticos paradójicos. Mientras la imagen de George W. Bush alcanzaba su cota más baja, una encuesta realizada pocos meses antes del cese de su mandato revelaba que casi dos de cada tres

\footnotetext{
25 “Transcript of President Bush's Prayer Service Remarks", National Day of Prayer and Remembrance for the Victims of the Terrorist Attacks on September 11, 2001, Washington National Cathedral, 14-09-2001, http://www.opm.gov/guidance/09-14-01gwb.htm, 12-09-2001.
} 
americanos (el 62 por ciento) reconocía la eficacia de su política antiterrorista ${ }^{26}$. El año electoral coincidió con la producción de $W$, tercera biografía fílmica de un presidente realizada por Oliver Stone, con la particularidad de que el protagonista aún vivía y que el estreno tuvo lugar apenas cuatro semanas antes de las elecciones. El director que había preconizando el período de Clinton con su retrato de Kennedy, cerraba ahora el de Bush con un biopic donde flotaba el fantasma de Nixon, otro presidente marcado por la guerra ${ }^{27}$.

La así llamada Era Obama arrancó mientras el cine de desastres, invasión y escenarios apocalípticos aún experimentaba el auge iniciado durante el mandato precedente. El año en que los demócratas regresaron a la Casa Blanca se habían estrenado siete películas de desastres en las que se eludía la figura presidencial excepto en dos -Wall-E y Conspiración del pánico-, en las que se le concedía un papel secundario y patético. Además, en 2008 también aparecieron las mencionadas $W$ y Frost/Nixon, donde se mostraban dos perfiles presidenciales especialmente críticos. Por último, el cine de Irak proporcionaba Red de mentiras y la aclamada En tierra hostil (Kathryn Bigelow).

A partir de 2005, el auge del cine de escenarios apocalípticos se manifiesta también en la taquilla estadounidense. Aquel año, La guerra de los mundos alcanzó el cuarto puesto en recaudación, mientras que otros blockbusters como Soy leyenda y El caballero oscurso obtuvieron el sexto y primer puesto de taquilla en sus respectivos años de producción. A lo largo de 2009 se inauguró una nueva tendencia de escenarios post-apocalípticos con títulos como 9 (Shane Acker 2009), The Road (John Hillcoat 2009), Zombieland (Ruben Fleischer 2009) y El Libro de Eli (Albert and Allen Hughes 2010). En este último, un viajero interpretado por Denzel Washington recorre América en el año 2043, reducida a escombros, para poner a salvo el último ejemplar de la Biblia en el único lugar del país donde la autoridad intenta recomponer la cultura perdida: no se trata de la Casa Blanca, el Capitolio o el Lincoln Memorial, sino el penal de Alcatraz.

Según Kellner, Denzel Washington integra, junto a Morgan Freeman y Will Smith, un trío de actores cuyo perfil épico predispuso a la opinión pública americana para aceptar el liderazgo de un presidente afro-americano28. De hecho, durante el segundo mandato de Bush, Will Smith interpretó en Soy leyenda al único personaje militar que realiza un acto de inmolación heroica para proteger América de una amenaza letal a gran escala. Tras el triunfo de Obama, en el cine también se advierte una tendencia a recuperar la imagen del ejército y del presidente, como si formara parte de un proceso de reconstrucción moral del país. Así, en el thriller de ciencia-ficción Código fuente (Duncan Jones 2011), un excombatiente de Irak en coma emplea su mínima actividad cerebral para evitar atentados terroristas dentro de su propio país.

Pero sin duda, 2012 (Roland Emmerich 2009) es el título de desastres más emblemático de la nueva etapa. En la película de Emmerich, la figura presidente afro-americano Thomas Wilson, interpretado por Danny Glover, parece diseñada para enmendar los errores que, a juicio de Hollywood, fueron cometidos durante la Administración Bush-Cheney. Algo que también podría entenderse como parte de la catarsis apocalíptica propia del género. Así, durante las jornadas previas al tsunami que amenaza con sumergir el planeta, Wilson activa todas las medidas posibles de seguridad y plantea el problema desde el punto de vista de la población que lidera. El presidente insiste en la idea de decir la verdad al pueblo, y esta actitud contrasta con la del gobernador de California Schwarzenegger, a quien se considera indigno de confianza en la película).

Wilson también transforma la Casa Blanca en un hospital de campaña, se niega a abandonar a su pueblo cuando le piden que suba a bordo del Air Force One y, finalmente, se reconcilia con su hija en una conversación que más bien parece un acto de disculpa por parte de la institución

26 "Reviewing the Bush Years".

${ }^{27}$ CARNEVALE, Rob, "W. Oliver Stone Interview", http://www.indielondon.co.uk/Film-Review/W-oliver-stoneinterview, 17-09-2011.

${ }^{28}$ KELLNER, Cinema Wars, op. cit., pp. 37-38. 
presidencial ante la nación, debido a los errores del pasado. Tanto Wilson como los heridos que abarrotan la mansión muestran sobre sus hombros las cenizas procedentes de la nube de un volcán, en clara referencia a las cenizas de los neoyorkinos durante el 11S. El detalle resulta significativo, pues se trata de la primera producción de Hollywood en la que el presidente de Estados Unidos presenta en su imagen los mismos signos del desastre que sus conciudadanos.

Finalmente, en una escena muy característica de Emmerich, la Casa Blanca termina destruida por una ola monumental y la última visión de Wilson es la imagen alegórica del USS John F. Kennedy antes de precipitarse sobre el edificio, como si el antiguo inquilino regresara al fin a casa.

\section{Conclusiones}

El cine de visos apocalípticos, que expresa audiovisualmente la amenaza del desastre o la catástrofe en sí misma, expone uno de los miedos inherentes en la cultura estadounidense a juicio de Stearns: la propia destrucción. Los atentados del 115 materializaron la idea del desastre -que ya antes el cine había puesto en imágenes-y, con ello, alimentaron la sensación de vulnerabilidad y el viejo temor secular. Este tipo de cine ha jugado un importante papel en la transformación de la imagen del presidente de Estados Unidos, icono de la unidad nacional y responsable de la seguridad del país. Sin embargo, este referente se ha difuminado progresivamente durante la primera década del siglo, dentro del contexto político y social derivado de los ataques del $11 \mathrm{~S}$.

De acuerdo con Doherty, las representaciones fílmicas del presidente durante los 90 habían recibido un tratamiento de condescendencia, desprecio, simpatía e idealismo. Con todo, el cine de escenario apocalíptico en particular proyectó una imagen heroica de la institución, amplificada por el amplio impacto de este tipo de producciones sobre la audiencia norteamericana. A lo largo de los mandatos demócratas, el retrato positivo del presidente coincidió con el apoyo mayoritario de la opinión pública a la gestión de Bill Clinton. Entre 1993 y 2001, dos arquetipos expresan la fuerza y el carisma del líder político: el presidente-soldado dispuesto al combate, y el presidente solidario que interviene activamente en la defensa de su país.

Durante los dos mandatos de George W. Bush, el discurso fílmico cambió notablemente. Pese al firme apoyo popular prestado al presidente tras el 11S, Hollywood no secundó esta tendencia y reflejó el progresivo deterioro del líder político en las encuestas. El cine -en especial en los escenarios apocalípticos- ignoró, devaluó y cuestionó la figura presidencial, y finalmente elaboró una reflexión crítica. Esta involución de la figura presidencial quedó expresada a través de tres figuras. En primer lugar, el presidente cobarde preocupado por carrera política, capaz de abandonar al pueblo durante la catástrofe: antítesis clara de los arquetipos predominantes antes del 11S. En segundo lugar, el presidente como parte del problema, que con su actuación o decisiones agrava la amenaza contra el país. Por último, el presidente ausente que se manifiesta a través de instituciones como el ejército o las agencias de seguridad. Pese a esta ausencia, la censura del discurso presidencial puede reconocerse en el cine popular a través de arquetipos como el fanático atrincherado. Así como Kennedy fue uno de los principales referentes en la década previa, la sombra de Nixon parecía inspirar a los cineastas como referente histórico del presidente controvertido por antonomasia.

El discurso inicial de Bush de la guerra contra el terror no encontró eco en el cine de escenario apocalíptico, donde la figura presidencial había alcanzado su proyección más amplia. Más aún: fue criticado a través de su simbolismo particular. Prueba de ello es el uso peculiar que se dio a dos elementos del imaginario apocalíptico: el papel del ejército como agente de destrucción, y el mencionado arquetipo del fanático atrincherado, que lleva hasta el extremo su tradicional miedo al castigo.

Más allá de los factores que pueden explicar este fenómeno de involución, las conexiones entre el tratamiento de la imagen presidencial, la tendencia mediática y el apoyo popular a la gestión política parecen fuera de toda duda. Además, constituyen un ejemplo significativo de los vínculos emocionales y retóricos entre cine y opinión pública a lo largo de las últimas décadas. 


\section{Bibliografía citada}

"ACLU Responds to Senate Passage of Anti-Terrorism Bill, Ashcroft Speech. Promises to Monitor Implementation of Sweeping New Powers", American Civil Liberties Union, 25-10-2001, http://www.aclu.org/natsec/gen/12464prs20011025.html, 22-09-2011.

"Most Americans Still Not Interested in 9/11 Movies", Gallup, 10-08-2006, http://www.gallup.com/poll/24070/most-americans-still-interested-911-movies.aspx>, 13-09-2011.

"Public Sees a Future Full of Promise and Peril", Pew Research Center for the People and the Press, 22-06-2010, http://people-press.org/2010/06/22/public-sees-a-future-full-of-promise-and-peril , 08-092011.

"President Delivers State of the Union Address", The White House, Office of the Press Secretary, 29.012002, http://georgewbushwhitehouse.archives.gov/news/releases/2002/01/print/20020129-11.html, $12-09-2011$.

"Presidential Approval Ratings: Bill Clinton", Gallup, http://www.gallup.com/poll/1 16584/presidentialapproval-ratings-bill-clinton.aspx, 09-09-2011.

"Reviewing the Bush Years and the Public's Final Verdict. Bush and Public Opinion", The Pew Research Center, 18-12-2008. http://people-press.org/2008/12/18/bush-and-public-opinion, 12-092011.

"Transcript of President Bush's Prayer Service Remarks", National Day of Prayer and Remembrance for the Victims of the Terrorist Attacks on September 11, 2001, Washington National Cathedral, 14-092001, http://www.opm.gov/guidance/09-14-01gwb.htm, 12-09-2011.

BARBOZA, C., "Imagination is infinite", USA Weekend, 19-06-2005, http://www.usaweekend.com/05_issues/050619spielberg.html, 09-11-2008.

CARNEVALE, Rob, "W. Oliver Stone Interview", http://www.indielondon.co.uk/Film-Review/W-oliverstone-interview, 18-09-2011.

CAWELTI, John, Adventure, Mystery and Romance: Formula Stories as Art and Popular Culture, University of Chicago Press, Chicago, 1976.

DIXON, Wheeler W., Visions of the Apocalypse: Spectacles of Destruction in American Cinema, Wallflower Press, Londres, 2003.

DOHERTY, Thomas "Movie Star Presidents", en Jon Lewis (ed.), The End of Cinema as We Know It. American Films in the Nineties, New York University Press, Nueva York, 2001, pp. 150-157.

GARCÍA FERNÁNDEZ, Emilio, y SÁNCHEZ GONZÁLEZ, Santiago, "Las imágenes de la historia en la obra de Stanley Kubrick", Área Abierta, n. 1, nov. 2011 , p. 1.

HAYES, Dade y MCCLINTOCK, Pamela, "War chores for H'w'd: White House, moguls agree to step up showbiz efforts", Variety, 11 Nov. http://www.variety.com/article/VR1 117855616 ? refcatid=18\&printerfriendly=true, 21-09-2001

KELLNER, Douglas, Cinema Wars. Hollywood Film and Politics in the Bush-Cheney Era, Wiley-Blackwell, Oxford, 2010.

KELLNER, Douglas, Media Spectacle and the Crisis of Democracy, Paradigm Press, Boulder (Colorado), 2005. 
KELLNER, Douglas, Media Culture: Cultural Studies, Identity and Politics between the Modern and the Postmodern, Routledge, Londres 1995.

KELLNER, Douglas y RYAN, Michael, Camera Politica: The Politics and Ideology of Contemporary Hollywood Film, Indiana University Press, Bloomington, 1988.

LEYLAND, Matthew, "The Village", sight \& Sound vol. 14 (n. 10), Oct 2004, pp. 69-70.

NELSON, Michael, "Evaluating the Presidency", M. Nelson (ed.), The Presidency and the Political System, CQ Press, Washington DC, 2006, pp. 1-27

SHARRET, Chris (ed.), Crisis Cinema: The Apocalyptic Idea in Postmodern Narrative Film, Maisonneuve Press, Washington DC, 1993.

STEARNS, Peter N., "Targeting American Fear", Revue Française d'Etudes Americaines, 3/2010, n. 125 , pP. 9-12.

STEARNS, Peter N., American Fear: The Causes and Consequences of High Anxiety. Routledge, Nueva York, 2006.

TINDALL, George B. y SHI, David E., America: A Narrative History, W.W. Norton \& Company, Nueva York, 2007.

THOMPSON, Kirsten Moana, Apocalyptic Dread: American Film at the Turn of the Millennium, State University of New York Press, Albany (Nueva York), 2007.

TURAN, Kenneth, "Mars Attacks!: Tim Burton's Plan 9", Los Angeles Times, 13-12-1996, http://articles.latimes.com/1966-12-13/entertainment/ca-8507_1_mars-attacks, 09-09-2011.

WOODWARD, Bob, Bush at War, Simon\&Schuster, Nueva York, 2002.

WOODWARD, Bob, State of Denial, Simon\&Schuster, Nueva York, 2006. 